\title{
The role of appropriate diagnostic testing in acute respiratory tract infections: An antibiotic stewardship strategy to minimise diagnostic uncertainty in primary care
}

\author{
A J Brink, ${ }^{1}$ MB ChB, MMed (Micro); J van Wyk, ${ }^{2}$ MB ChB, MMed (Clin Path); V M Moodley, ${ }^{2}$ MB ChB, DTM\&H, FCPath (Micro) SA, \\ MMed (Micro); C Corcoran, ${ }^{3}$ MB ChB, FCPath (Virol), DTM\&H, MMed (Virol); P Ekermans, ${ }_{4}^{4}$ MB ChB, DTMH, MMed (Clin Path); \\ L Nutt, ${ }^{5}$ MB ChB, MMed (Clin Path); T Boyles, ${ }^{6}$ MA, BM BCh, MRCP, MD, DTM\&H, Cert ID SA; O Perovic ${ }^{7,8}$ FC Path (SA) (Micro), \\ MMed (Micro), DTM\&H, MD; C Feldman, ${ }^{9}$ MB BCh, DSc, PhD, FRCP, FCP (SA); G A Richards, ${ }^{10}$ MB BCh, PhD, FCP (SA), FRCP; \\ M Mendelson, ${ }^{6} \mathrm{BSc}, \mathrm{PhD}, \mathrm{MBBS}, \mathrm{FRCP}, \mathrm{DTM} \& \mathrm{H}$
}

${ }^{1}$ Ampath National Laboratory Services, Milpark Hospital, Johannesburg, South Africa

${ }^{2}$ Ampath National Laboratory Services, Cape Town, South Africa

${ }^{3}$ Department of Molecular Biology, Ampath National Reference Laboratory, Centurion, South Africa

${ }^{4}$ Department of Clinical Microbiology, Ampath National Reference Laboratory, Centurion, South Africa

${ }^{5}$ Ampath National Laboratory Services, Port Elizabeth, South Africa

${ }^{6}$ Division of Infectious Diseases and HIV Medicine, Department of Medicine, Groote Schuur Hospital and Faculty of Health Sciences, University of Cape Town, South Africa

${ }^{7}$ Centre for Opportunistic, Tropical and Hospital Infections, National Institute for Communicable Diseases, Johannesburg, South Africa

${ }^{8}$ Department of Clinical Microbiology and Infectious Diseases, School of Pathology, Faculty of Health Sciences, University of the Witwatersrand, Johannesburg, South Africa

${ }^{9}$ Division of Pulmonology, Charlotte Maxeke Johannesburg Academic Hospital and Faculty of Health Sciences, University of the Witwatersrand, Johannesburg, South Africa

${ }^{10}$ Department of Critical Care, Charlotte Maxeke Johannesburg Academic Hospital and Faculty of Health Sciences, University of the Witwatersrand, Johannesburg, South Africa

Corresponding author: A M Brink (brinka@ampath.co.za)

\begin{abstract}
Antibiotic resistance has increased worldwide to the extent that it is now regarded as a global public health crisis. Interventions to reduce excessive antibiotic prescribing to patients can reduce resistance and improve microbiological and clinical outcomes. Therefore, although improving outpatient antibiotic use is crucial, few data are provided on the key interventional components and the effectiveness of antibiotic stewardship in the primary care setting, in South Africa. The reasons driving the excessive prescription of antibiotics in the community are multifactorial but, perhaps most importantly, the overlapping clinical features of viral and bacterial infections dramatically reduce the ability of GPs to distinguish which patients would benefit from an antibiotic or not. As a consequence, the need for tools to reduce diagnostic uncertainty is critical. In this regard, besides clinical algorithms, a consensus of collaborators in European and UK consortia recently provided guidance for the use of C-reactive protein point-of-care testing in outpatients presenting with acute respiratory tract infections (ARTIs) and/or acute cough, if it is not clear after proper clinical assessment whether antibiotics should be prescribed or not. A targeted application of stewardship principles, including diagnostic stewardship as described in this review, to the ambulatory setting has the potential to affect the most common indications for systemic antibiotic use, in that the majority (80\%) of antibiotic use occurs in the community, with ARTIs the most common indication.
\end{abstract}

S Afr Med J 2016;106(6):554-561. DOI:10.7196/SAMJ.2016.v106i6.10857

Antibiotic resistance (ABR) is a critical threat to public health globally that, if unchecked, could result in 10 million deaths per year at a cumulative cost of USD100 trillion by $2050 .^{[1]}$ Overuse and misuse of antibiotics has resulted in the emergence of multidrugresistant (MDR), extensively drug-resistant (XDR) and pan-drugresistant (PDR) bacteria, which are increasingly common in South Africa (SA). ${ }^{[2]}$ To alleviate the crisis, antibiotic stewardship (AS) has emerged as a concept that embodies the appropriate use of antibiotics with the goal of optimising patient outcomes while reducing the emergence of resistant bacteria ${ }^{[3]}$

The majority (75-80\%) of antibiotics for systemic use in adults and children are prescribed in the community, with acute respiratory tract infections (ARTIs) such as bronchitis, pharyngitis and sinusitis the most common indications. ${ }^{[4-7]}$ Although most ARTIs are of viral origin and are self-limiting, so non-antibiotic treatment options should be preferred, they still account for most of the antibiotics prescribed in primary healthcare. It is estimated that almost $60 \%$ of patients with an ARTI receive an unnecessary antibiotic, which is unlikely to be of benefit. ${ }^{[5,6,8-10]}$

The reasons for the excessive prescription of antibiotics in the community are complex and include the lack of a precise diagnosis of the cause of the presenting respiratory illness, perceived patient and parental preference for the receipt of an antibiotic, and a lack of appreciation of the negative impact of unnecessary prescriptions, particularly with regard to the development of resistance in the community. Fear of litigation, both consciously and unconsciously, may also be a factor. Perhaps equally important are constraints on the time available to perform a full clinical assessment and 
the considerable diagnostic uncertainty that arises as a consequence of overlapping clinical features between bacterial and viral infections and even non-infectious respiratory illnesses. ${ }^{[10,11]}$

This problem is exacerbated in community practice by the lack of availability of sensitive, specific and cost-effective tests to distinguish viral from bacterial infections. Even the presence of bacteria at the site of a suspected infection does not necessarily identify whether it is bacterial or not, as without evidence of inflammation it probably represents colonisation or contamination. ${ }^{[12,13]}$ This implies that a good clinical history and examination alone may not be sufficient, and the judicious use of biomarkers, such as point-of-care testing (POCT) for C-reactive protein (CRP), may aid in diagnosis and thus reduce antibiotic consumption. ${ }^{[11]}$

The purpose of this review is to provide a simple framework for clinical decisionmaking regarding antibiotic use and, where applicable, the appropriate use of laboratory tests for common ARTI syndromes in primary practice. This 'diagnostic stewardship' should be a key component of AS, providing assistance to clinicians in everyday practice to differentiate bacterial from viral infections or non-infectious conditions and, in so doing, boosting confidence in decisionmaking. Conceptually, this review should be understood as one strategy within a multimodal primary care AS programme with the ultimate aim of reducing redundant antibiotic use (Fig. 1). ${ }^{[14]}$

\section{Patients presenting with acuite cough}

Acute cough, defined as lasting <3 weeks (and without more worrying features such as haemoptysis, weight loss or other symptoms of tuberculosis, chest pain or a history of aspiration) is estimated to represent the most common cause for consultation with a general practitioner (GP) and one of the commonest reasons for prescription of antibiotics in community practice; in one study, $52.7 \%$ of adult patients presenting with acute cough received an antibiotic. ${ }^{[15]}$ This is despite Whaley et al. ${ }^{[16]}$ having recently demonstrated that the most common infective causes of acute cough were viral: the common cold, nonspecific upper respiratory tract infections (URTIs) and acute bronchitis, for which antibiotic therapy is not indicated. Non-infectious conditions causing cough include postnasal drip from allergic rhinitis, gastro-oesophageal reflux, smoking, angiotensin-converting enzyme inhibitors and undiagnosed asthma. The symptoms of an acute cough can take up to 3 weeks to settle, and it is this prolonged duration that often precipitates the initial antibiotic prescription (and possibly even a second one), out of desperation either on the part of the patient or the doctor. ${ }^{[17]}$

\section{The common cold}

It should be understood that the clear nasal secretions characteristic of the common cold frequently become purulent without signifying superimposed bacterial infection (Fig. 2). This is a common misperception and hence, even with coughing, which is a normal accompaniment of a postnasal drip, antibiotics are not required. ${ }^{[8]}$ Patients should be advised that the average duration of the illness (before and after seeing the doctor) is in the region of $10-11$ days. ${ }^{[17]}$ Obtaining nasal swabs for culture is strongly discouraged even if the cough is persistent, and is particularly wasteful in resource-challenged low- and middle-income countries.

Only symptomatic treatment should be provided, which may include analgesics such as paracetamol (for relief of fever, headache or sinus discomfort). Aspirin should be avoided in children $<18$ years of age because of the risk of Reye's syndrome. In those $\geq 12$ years of age, oral or topical decongestants may relieve rhinorrhoea and nasal congestion; however, these should not be used for $>5$ days as longer durations may lead to rebound congestion known as rhinitis medicamentosa. Early use of a nasal steroid may reduce the duration of the postnasal drip-induced cough.

\section{Acute bronchitis}

Clinically, it can be difficult to differentiate acute bronchitis from other conditions that may present with cough. ${ }^{[18]}$ The major differential diagnosis is community-acquired pneumonia (CAP), which does require antibiotics (Fig. 3). However, the presentation is very similar to that of the common cold. ${ }^{[19]}$ The latter is usually associated with nasal congestion and rhinorrhoea and typically lasts only $7-10$ days, but it is important to recognise that bronchitis also seldom occurs in isolation as it frequently results from a 'sinobronchitis' occurring as a consequence of a virally induced postnasal drip. The

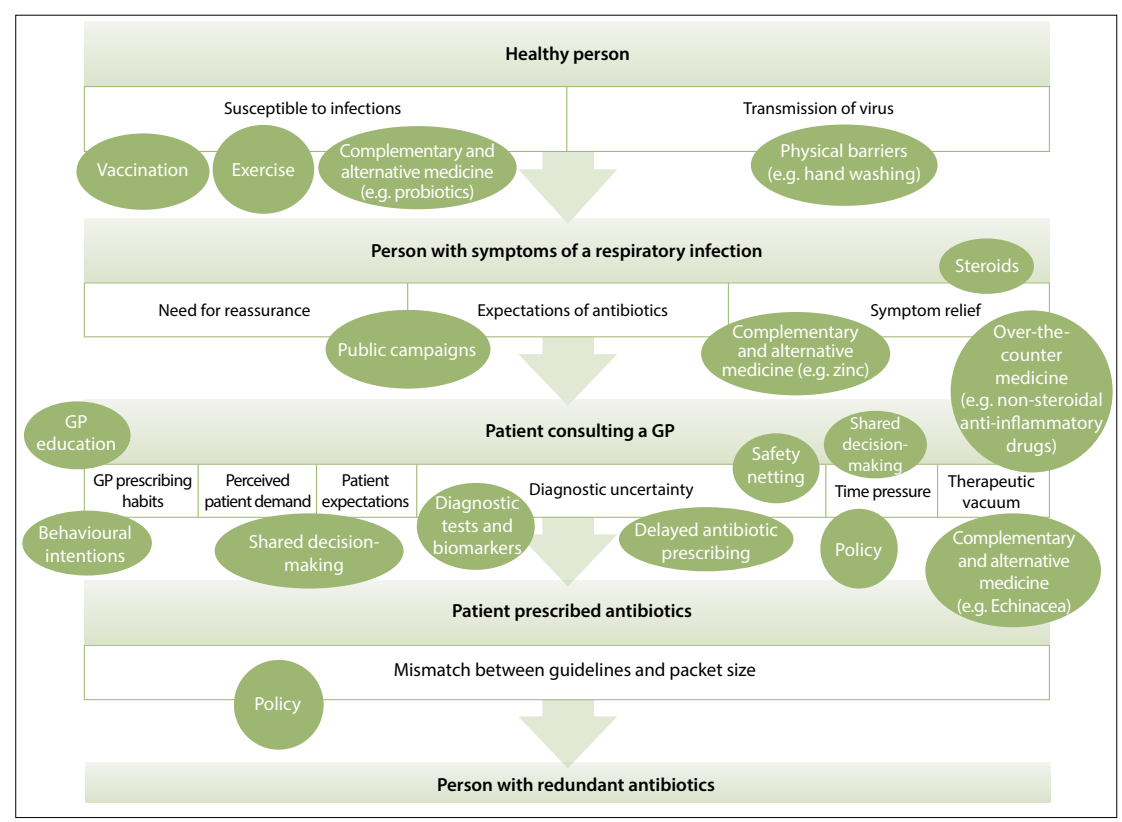

Fig. 1. Overview of strategies to minimise antibiotic use in primary care at each stage of the path from healthy person to antibiotic prescription (reproduced with permission from Hansen et al. ${ }^{[14]}$ ).

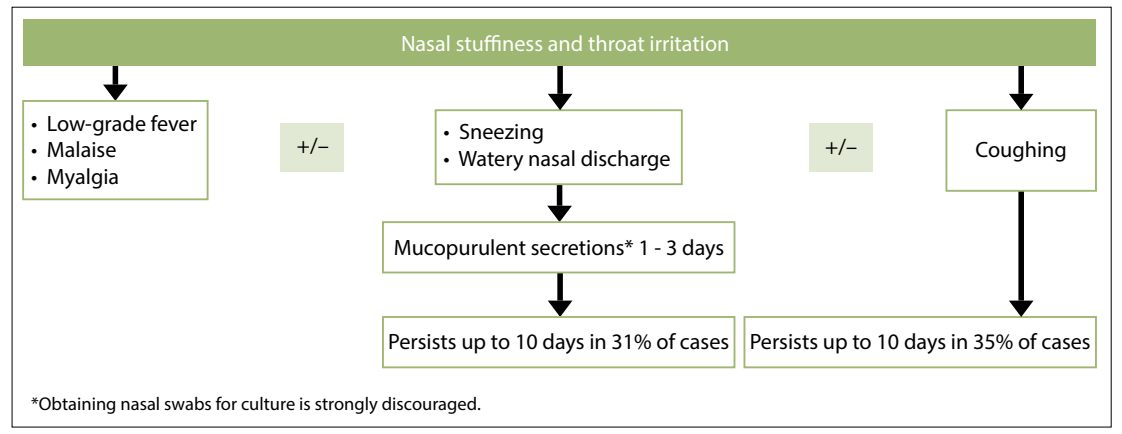

Fig. 2. Natural history of the common cold. ${ }^{[8]}$ 
presence of discoloured sputum should also not be used as an indicator of bacterial as opposed to viral infection, as both of these, and also non-infectious conditions such as asthma, frequently present with purulent or purulent-looking sputum. ${ }^{[18]}$

In most cases, history and physical examination are sufficient to identify more serious conditions requiring chest radiography (CXR). Only in select circumstances may additional diagnostic testing be required. If it is suspected that an outbreak of bronchitis may be due to Mycoplasma pneumoniae or Chlamydophila pneumoniae, especially when presenting in young adults, a specimen for molecular confirmation may be warranted. A swab for Bordetella pertussis polymerase chain reaction (PCR) is warranted in unvaccinated patients with a paroxysmal or 'whooping' cough. $^{[18]}$
Data are limited regarding the management of acute bronchitis in children. Most would regard it as an extension of a nonspecific viral URTI and no laboratory testing would be advised. Microscopy, culture and sensitivity (MC\&S) on sputum specimens is strongly discouraged, as antibiotics may inappropriately be prescribed for growth of colonisers or normal flora. Perhaps the most important feature of a more severe condition requiring a CXR is tachypnoea.

Antibiotics do not alter the natural course of acute bronchitis and should not be prescribed unless comorbid risk factors are present ${ }^{[18]}$ (Fig. 3). Despite most cases being viral in origin, doctors in the USA continue to prescribe antibiotics to adults with this diagnosis despite clear-cut guideline recommendations to the contrary. ${ }^{[16]}$ In fact, despite significant interventions, including

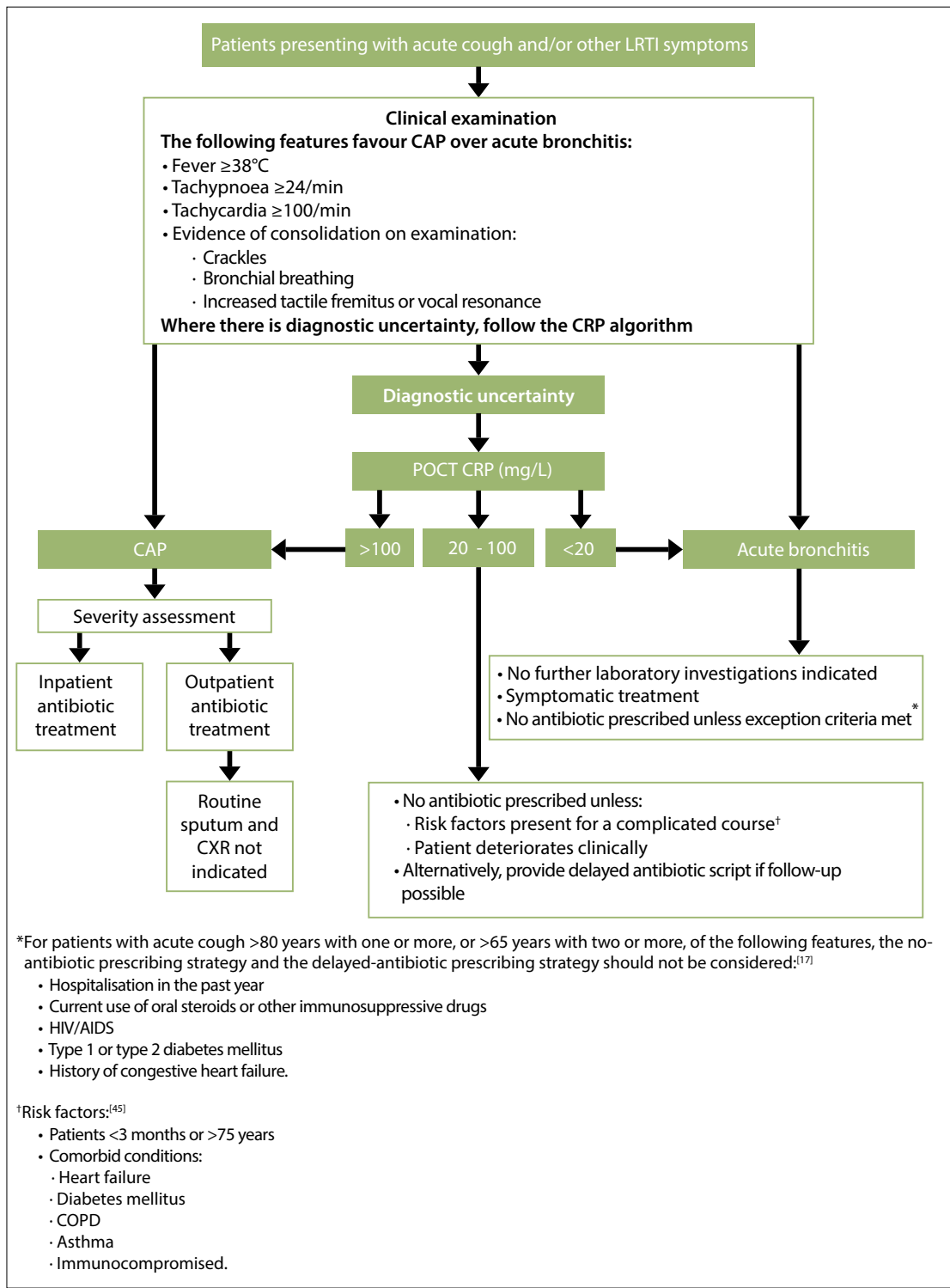

Fig. 3. The use of POCT CRP measurement to distinguish CAP from acute bronchitis in the primary care setting. guidelines, quality measures and more than 15 years of educational effort by the Centers for Disease Control and Prevention (CDC), the antibiotic prescribing rates for acute bronchitis, which should be zero, have remained at $71 \%$ and even increased between 2006 and 2010. ${ }^{[20]}$

Management should include advice to the patient as to the benign nature and course of the condition, with the potential for symptom resolution to take up to 3 weeks, together with a nasal steroid and with instructions for the patient to return should symptoms fail to resolve or if pyrexia, pleuritic chest pain or haemoptysis develop. A macrolide antibiotic should be prescribed for confirmed B. pertussis infections and, although it has limited symptomatic effect, it does reduce the risk of transmission.

\section{Acute pharyngo- tonsillitis}

Respiratory viruses are the most common causes of acute pharyngitis/tonsillitis, while group A $\beta$-haemolytic streptococci (GABHS) (Streptococcus pyogenes) is the most important bacterial pathogen; these account for $15 \%$ and $40 \%$ of adult and paediatric cases, respectively. ${ }^{[21,22]}$ It is important to note that asymptomatic carriage of GABHS occurs in up to $20 \%$ of children and in up to $5 \%$ of adolescents and young adults. ${ }^{[23]}$

Certain clinical features may assist in distinguishing viruses from GABHS (Fig. 4), and several clinical prediction rules to diagnose GABHS have been published. ${ }^{[24]}$ However, reliance on these rules alone may still lead to antibiotic overprescription. ${ }^{[25]}$ Currently, rapid antigen testing (RADT) methods have not been validated in SA and are therefore not routinely available. In a recent meta-analysis, the accuracy of RADT in children with pharyngitis selected as likely to have GABHS by means of clinical prediction rules, ranged from $24 \%(95 \%$ confidence interval (CI) 21 - 27) to $86 \%(95 \%$ CI 84 - 89). ${ }^{[25]}$ According to the authors, none of 16 RADTs tested had good correlation with the diagnosis of GABHS by culture, particularly as the disease spectrum, the size of the bacterial inoculum and the skill of the operator all affect test performance. ${ }^{[25,26]}$ Molecular methods, including PCR, offer the highest accuracy for GABHS detection (approaching 95 - 100\%), but widespread use is limited by limited resources. ${ }^{[25]}$

CRP POCT does not distinguish between those who do or do not require antibiotic therapy ${ }^{[27]}$ In addition, CRP values of 10 $60 \mathrm{mg} / \mathrm{L}$ measured in the laboratory may not be able to distinguish between viral and bacterial pathogens in patients with symptoms of $<7$ days' duration. ${ }^{[28]}$ Although measurement 
of the absolute neutrophil count may increase diagnostic accuracy for GABHS when rapid antigen testing is not available, routine use is also not recommended; ${ }^{[29]}$ nor are antistreptococcal antibody titres, as they reflect past and not current infections. ${ }^{[30]}$ Taking all these factors into account, the diagnostic and antibiotic treatment criteria are summarised in Fig. 4. Correctly performed throat cultures are still considered the gold standard for the diagnosis of acute GABHS pharyngotonsillitis, with a high sensitivity of $90-95 \% \cdot{ }^{[30]}$ To achieve this, it is recommended that the tonsils and posterior pharyngeal wall be vigorously swabbed. ${ }^{[21]}$

It is important to note that a delay in antibiotic prescription pending availability of culture results does not reduce efficacy in the prevention of acute rheumatic fever and, as such, a delayed antibiotic prescription strategy is advised for all patients where a throat swab has been sent for MC\&S. However, throat swabs for confirmation of GABHS may not be feasible in many SA settings owing to increased direct and indirect financial costs and the need for additional healthcare visits. In such cases, empirical antibiotic therapy is advised for all patients aged $3-21$ years who fit the clinical prediction rules. Generally speaking, the mainstay of the management of acute pharyngitis is symptomatic and includes adequate analgesia and antipyretics.

\section{Acute otitis media}

Correct clinical diagnosis of acute otitis media (AOM) is the key to reducing overall antibiotic prescribing for this very common condition. Approximately $75 \%$ of children have had at least one episode by 3 years of age. ${ }^{[8]}$ Time and clinical acumen is required to visualise the eardrum. Symptom presentation varies with age and, because typical symptoms overlap with other conditions, a clinical history alone is insufficient to predict whether AOM is present or not. To confirm the diagnosis, inflammation of the eardrum and a middle ear effusion, i.e. fullness, bulging, cloudiness and redness of the tympanic membrane (TM), must be identified (Fig. 5).

Although redness of the TM is an early sign of otitis media, it is not diagnostic on its own as there are numerous other causes, including crying, otitis externa, myringitis and barotrauma. ${ }^{\left[{ }^{8]}\right.}$ As a consequence, $\mathrm{AOM}$ is frequently mis- or overdiagnosed. Although clear visualisation of the TM is difficult at times, and because AOM is typically self-limiting, a high degree of diagnostic certainty is essential to minimise antibiotic overuse. Previous studies have shown that

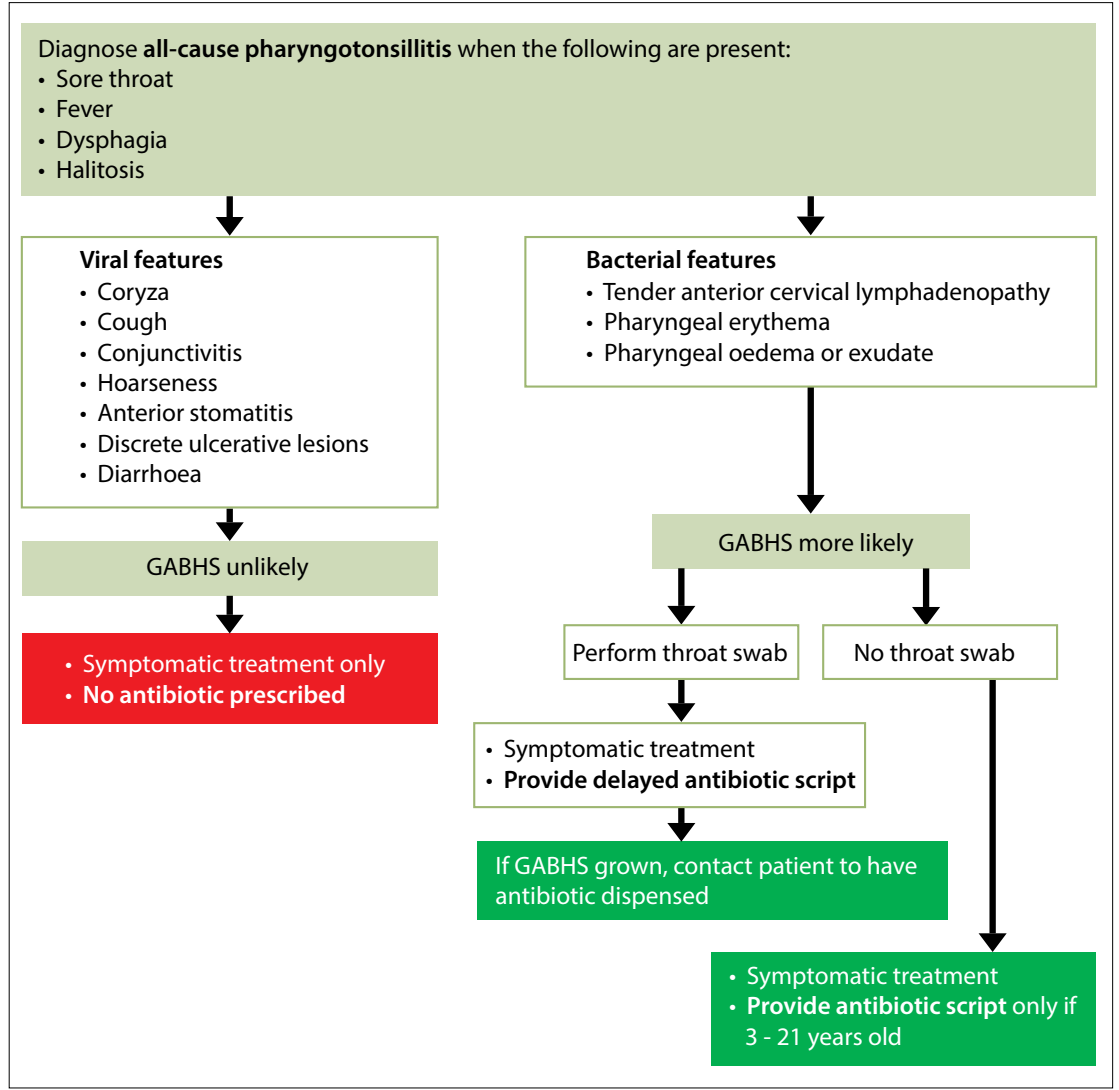

Fig. 4. Diagnostic and treatment criteria for acute pharyngotonsillitis.

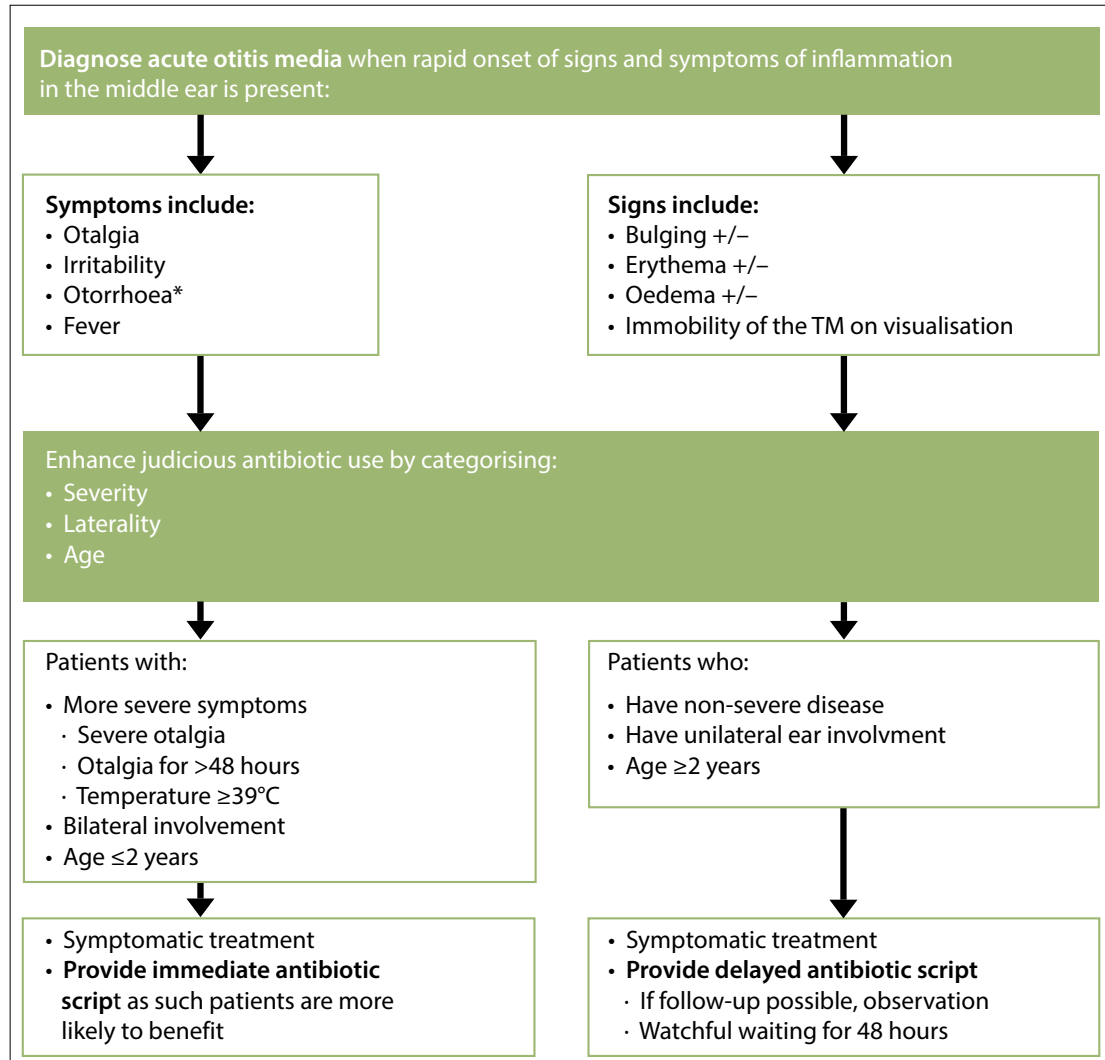

*Obtaining swabs and/or aspirations of otorrhoea (clear or purulent secretions) from a fresh tympanic perforation that is neither chronic nor recurring, in patients without prior exposure to antibiotics, is not routinely advised.

Fig. 5. Diagnostic and treatment criteria for acute otitis media. 
with correct diagnosis unnecessary antibiotic use can be reduced by up to $66 \% .^{[31]}$ Pneumotoscopy and tympanometry are very useful in determining the presence of a middle ear effusion. Routine tympanocentesis on children with uncomplicated otitis is not feasible because of ethical and resource-related considerations. Swabs and/ or aspirations of otorrhoea (clear or purulent secretions) that are neither recurring nor chronic, from a fresh tympanic perforation in patients without prior exposure to antibiotics, are also not routinely advised. However, with cases of AOM that closely follow swimming in children with perforations or grommets, an MC\&S is very useful in excluding Pseudomonas aeruginosa that might be critical. Of note, CRP is unhelpful in determining whether antibacterial therapy can be withheld.

As AOM is often viral in aetiology (50\% of cases) and with most bacterial cases (commonly S. pneumoniae, Haemophilus influenzae) resolving spontaneously, treatment of pain is the most critical aspect of the management of AOM. Antibiotics may be deferred for 48 hours in children $\geq 2$ years of age while symptomatic therapy is administered (particularly where good follow-up is possible) if there is unilateral involvement and if the disease is not severe ${ }^{[8,32]}$ (Fig. 5). Antibiotic prophylaxis in recurrent cases is of no value.

\section{Acuite bacterial rohin osinusitis}

Acute bacterial rhinosinusitis (ABRS) is usually preceded by a viral URTI (Fig. 6). Allergy, trauma, dental infection or other factors that cause inflammation of the nose and paranasal sinuses may also predispose individuals to ABRS. ${ }^{[8]} \mathrm{A}$ raised CRP has been suggested as a potential discriminator between coryza and sinusitis, but absolute values have not been validated. ${ }^{[11]}$

Attempts to establish an aetiological diagnosis of sinusitis are typically reserved for patients who have not responded to conventional medical treatment within $48-72$ hours, immunocompromised patients and those with complications. Sinus puncture and aspiration are the reference standard for a bacteriological diagnosis of ABRS. As most studies have shown poor correlation between nose and throat cultures and maxillary sinus aspirates, nasal or nasopharyngeal swabs are not recommended; neither is the use of X-rays, which is strongly discouraged.

A recent meta-analysis of treatment outcomes for ABRS has shown marginal benefit of antibiotics over placebo. ${ }^{[33]}$ Overall, the number needed to treat for one adult to benefit is 13 (95\% CI 9 - 22). Neither topical nor oral decongestants and/or antihistamines are recommended as adjunctive treatment, whereas both intranasal irrigation with either physiological or hypertonic saline and intranasal corticosteroids are recommended, the latter primarily in patients with allergic rhinitis.

\section{Influenza}

Influenza epidemics occur every year in SA during winter, typically from April to September, and should be considered in the differential diagnosis during this period. The clinical presentation varies from asymptomatic to severe and life-threatening infections. Typical and atypical presentations are depicted in Fig. $7{ }^{[34]}$ The clinical diagnosis of influenza is often difficult and unreliable and, where indicated, laboratory testing should be performed. ${ }^{[35]}$ Situations where this is necessary include where there is a cluster of cases in institutions such as nursing homes, or in severe illness, where neuraminidase inhibitors (such as oseltamivir) are indicated. The latter appears to provide only marginal benefit in the non-hospitalised (in contrast to the hospitalised) patient in the community and is not recommended outside of highly immunocompromised patients or those with severe chronic respiratory, cardiac or neurological conditions. ${ }^{[36]}$ The laboratory test of choice is a respiratory tract PCR on

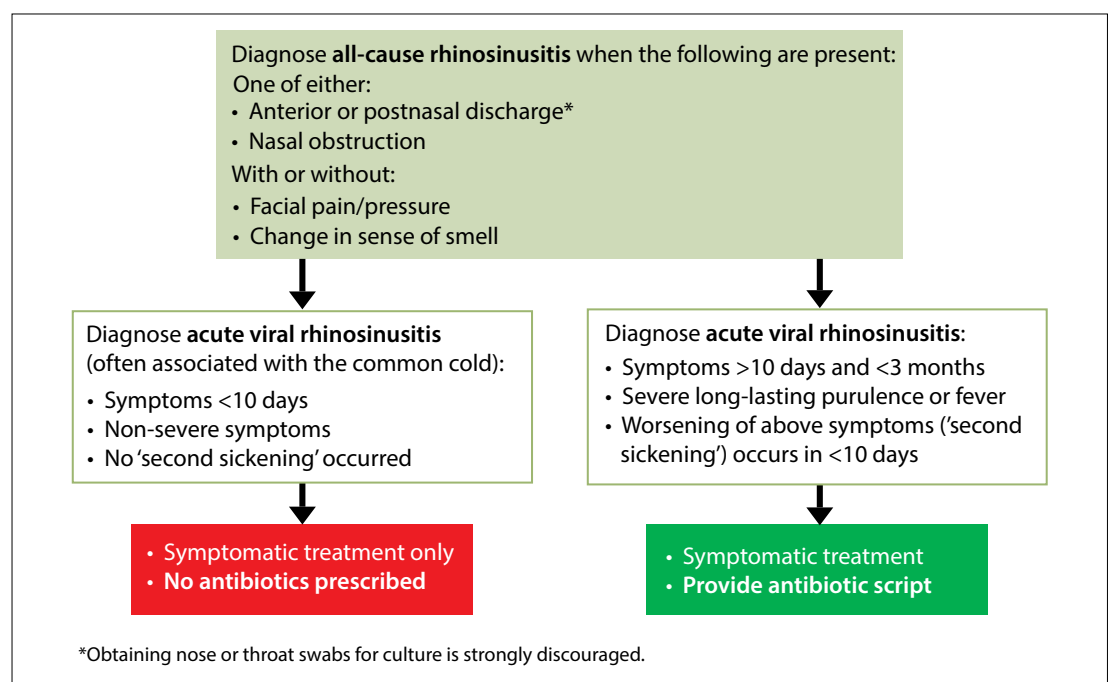

Fig. 6. Diagnostic and treatment criteria for acute bacterial rhinosinusitis.

\begin{tabular}{|c|c|}
\hline $\begin{array}{l}\text { Diagnos } \\
\text { Acute on } \\
\text { - High fe } \\
\text { - Headac } \\
\text { - Myalgi } \\
\text { - Dry co }\end{array}$ & $\begin{array}{l}\text { - High fever } \\
\text { - Headache } \\
\text { - Myalgia } \\
\text { - Dry cough }\end{array}$ \\
\hline $\begin{array}{l}\text { Atypical presentation in children may include: } \\
\text { - Nausea } \\
\text { - Vomiting } \\
\text { - Diarrhoea }\end{array}$ & $\begin{array}{l}\text { In the elderly, influenza may present as: } \\
\text { - Confusion } \\
\text { - Drowsiness }\end{array}$ \\
\hline \multicolumn{2}{|c|}{$\begin{array}{l}\text { Laboratory testing is only indicated for those for whom specific antiviral therapy (e.g. oseltamivir) } \\
\text { is recommended, namely: } \\
\text { - Those with severe or complicated infection } \\
\text { - Institutionalised patients } \\
\text { - Those at high risk of developing severe or complicated infections }\end{array}$} \\
\hline $\begin{array}{l}\text { The laboratory test of choice is influenza PCR: } \\
\text { - On a nasopharyngeal swab } \\
\text { - Alternatively, on a throat or nasal swab }\end{array}$ & $\begin{array}{l}\text { High-risk patients include: } \\
\text { - Pregnant women } \\
\text { - Age } \geq 65 \text { years } \\
\text { - Age } \leq 2 \text { years } \\
\text { - Chronic respiratory disease } \\
\text { - Significant cardiovascular disease } \\
\text { - Chronic renal or hepatic disease } \\
\text { - Obesity } \\
\text { - Diabetes melltus } \\
\text { - Immunosuppression, including HIV infection } \\
\text { - Asthma }\end{array}$ \\
\hline
\end{tabular}

Fig. 7. Diagnostic and treatment criteria for influenza. 
a nasopharyngeal swab. Rapid tests are not recommended, as their sensitivity is often low and negative results do not exclude the diagnosis. ${ }^{[37]}$

\section{Acute exacerbations of chronic obstructive pullmonary disease}

With regard to chronic obstructive pulmonary disease (COPD), there are two situations in which antibiotics may be used. The first is for the treatment of acute exacerbations of COPD (AECOPD), which is the focus of this section. The second is long-term antibiotic use for COPD patients who continue to have recurrent exacerbations despite optimal COPD treatment; description of this is beyond the scope of this article.

For AECOPD, antibiotics are not always required and there is still uncertainty as to which patients would benefit most from antibiotic use. Up to $60 \%$ of AECOPD is said to be due to airway infection, but not all of these are bacterial, and viral infections play a significant role. ${ }^{[38]}$ In general terms, however, antibiotic use appears to be of more value in patients with more severe COPD and in those with more severe exacerbations of COPD. Severity of AECOPD is usually classified using the Anthonisen criteria. ${ }^{[39]}$ Type 1 exacerbations, which are considered to be severe, have all three cardinal symptoms: increasing dyspnoea, increasing sputum volume and sputum purulence, while type 2 exacerbations (moderate exacerbations) have two of those three symptoms and type 3 exacerbations have one of the symptoms together with one other symptom such as URTI, fever, wheeze, cough, or increased respiratory or heart rate. ${ }^{[39]}$ The recommendations for routine antibiotic use in non-hospitalised patients and CRP testing are summarised in Fig. $8 .^{[40-42]}$

\section{Community-acquired pneumonia}

Most definitions of CAP include symptoms of an LRTI (productive cough, pleuritic pain and dyspnoea) and focal chest signs (dullness to percussion, bronchial breathing and crackles), as well as systemic features such as tachypnoea, tachycardia and a temperature of $\geq 38^{\circ} \mathrm{C}$. ${ }^{[43]}$ These features are, however, nonspecific and can be present in other infections, such as acute bronchitis, acute sinusitis and non-infectious conditions, although tachypnoea and tachycardia are uncommon. Symptoms and signs are also often less pronounced in elderly patients. ${ }^{[44]}$ If there is doubt as to the diagnosis, ${ }^{[45]}$ POCT of CRP may be helpful and is discussed below and depicted in Fig. 3 .
Routine CXR is not always available in primary care. If readily available, an X-ray is recommended if the signs and symptoms of CAP, as described above, are present or the POCT CRP is $>100 \mathrm{mg} / \mathrm{L}$, and if the diagnosis is uncertain. The former is useful to exclude conditions other than pneumonia such as empyema, lung abscess and bronchiectasis. Owing to low sensitivity, routine microbiological tests such as Gram staining, sputum or blood cultures are also not indicated for the management of outpatients with low-severity CAP. ${ }^{[43,46,47]}$ In children, urinary pneumococcal antigen testing is not recommended for the diagnosis of pneumococcal pneumonia owing to a high rate of false-positive results. ${ }^{[46]}$

\section{Outpatient v. inpatient management: Severity assessment}

In adults, once a clinical diagnosis of CAP has been made the primary care doctor should establish the optimal site for therapy (outpatient or inpatient) using clinical judgement together with a severity-of-illness score such as the CURB-65 or CRB-65. ${ }^{[17,48]}$ According to Bradley et $a l,{ }^{[46]}$ severity assessment for children aged $\geq 3$ - 6 months should also be performed on the grounds of the presence or absence of major and minor risk factors, but this is complex and may require referral. ${ }^{[49]}$

\section{The role of biomarkers in differentiating types of ARTI}

There is increasing evidence of a role for biomarkers, such as CRP and procalcitonin
(PCT), in the management of patients presenting with ARTI. ${ }^{[45]}$ In fact, a recent Cochrane review concluded that POCT for biomarkers (e.g. CRP) to guide antibiotic treatment of ARTIs in primary care can reduce antibiotic use and be used as an adjunct to a doctor's clinical examination; this reduction in antibiotic use did not affect patient-reported outcomes, including recovery from and duration of illness. ${ }^{[45,50]}$

PCT is produced primarily by the C cells of the thyroid gland. Markedly raised levels are seen with bacterial infections and only minimal increases are reported with viral infections, which, through the stimulation of interferongamma, inhibit PCT release. Conditions such as asthma or allergic rhinitis also do not result in PCT release. However, PCT lacks accuracy in less severely ill patients with ARTI seen in primary care ${ }^{[51]}$ and does not perform any better than a POCT CRP measurement in this setting. ${ }^{[4]}$ Because the negative predictive value for exclusion of bacterial infection is enhanced only by serial measurements and by concomitant negative cultures, and because rapid PCT testing on uncentrifuged venous blood is not readily available, this test is currently unlikely to influence management of RTI in primary care. ${ }^{[51,52]}$

In contrast, where there is diagnostic uncertainty, measurement of CRP levels can assist the physician in the management of patients presenting with features of ARTI. Recommendations for the use of CRP are based on reports from two large research groups: the IMPAC3T programme and the

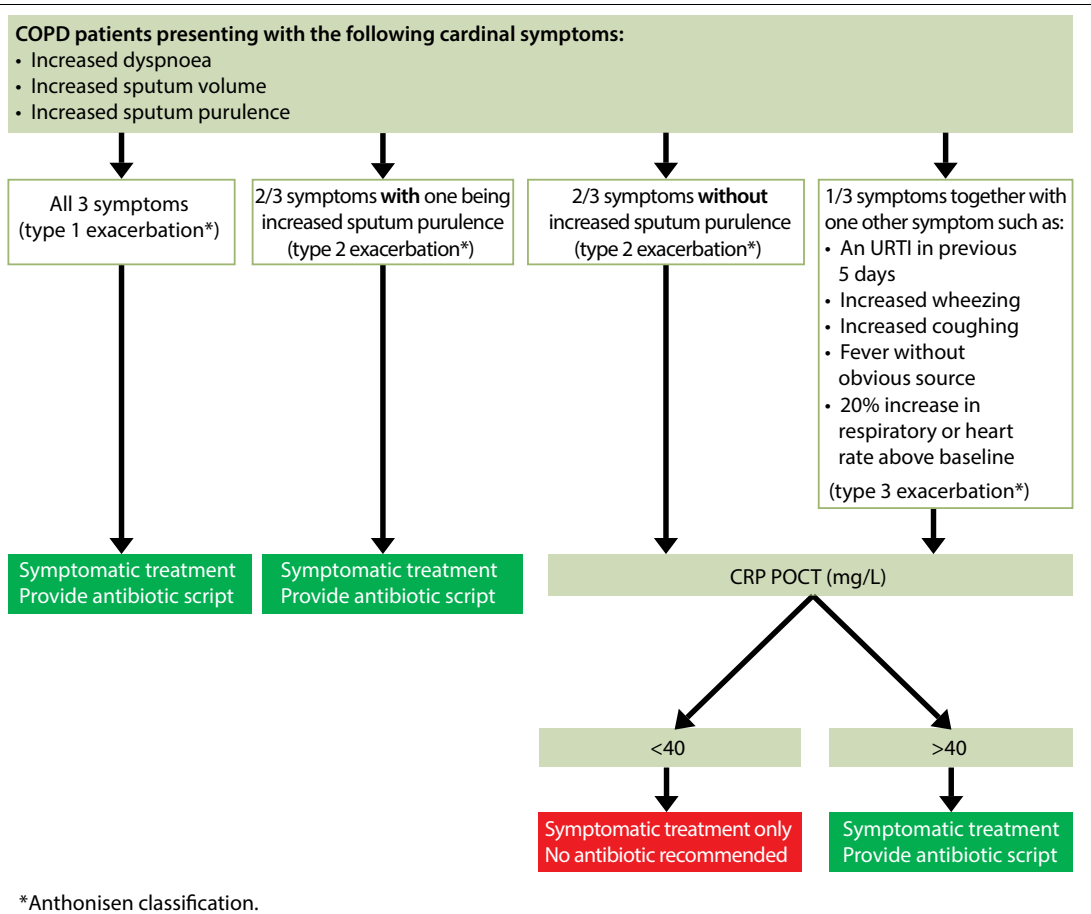

Fig. 8. Recommendations for antibiotic use in non-hospitalised patients with AECOPD. ${ }^{[40-42]}$ 
GRACE consortium study. These studies, incorporated into the 2014 NICE guidelines, ${ }^{[53]}$ are very useful in providing evidence to support the clinician who is uncertain as to whether to include antibiotics in the management of LRTI or not. ${ }^{[45]}$

Based on POCT CRP level measurement, the following is recommended (Fig. 3):

- CRP <20 mg/L: CAP is unlikely, and antibiotic therapy is not routinely indicated

- CRP 20 - 100 mg/L: A watchful waiting approach is recommended, where antibiotic prescription is provided only if the clinical condition deteriorates and if comorbid risk factors are present. These would include age $<3$ months or $>75$ years; in children, cardiovascular and pulmonary conditions (except asthma); and in adults, heart failure, severe COPD, diabetes mellitus (especially with use of insulin), neurological conditions, severe renal insufficiency or immune compromise

- $\mathrm{CRP}>100 \mathrm{mg} / \mathrm{L}$ : CAP is more likely, and antibiotic therapy would be appropriate. ${ }^{[53-55]}$

These cut-offs should be used as a guide, and CRP values should not be utilised in isolation without a clinical examination. Of note, it is also possible that viral infections, including uncomplicated influenza, may present with CRP values $>100 \mathrm{mg} / \mathrm{L} .{ }^{[56,57]}$

It is also useful to use CRP to identify patients presenting with AECOPD who are most likely to benefit from antibiotics. In one study of AECOPD comparing amoxicillin/clavulanate with placebo, the best CRP cut-off for predicting clinical failure in the placebo arm was $40 \mathrm{mg} / \mathrm{L}$, with an area under the curve of 0.732 (95\% CI 0.614 0.851) ${ }^{[42]}$ (Fig. 8).

The practical implications and considerations for POCT CRP in the SA setting that warrant closer attention include:

- Validation/verification of the POCT CRP assay used (to confirm the performance specifications as specified by the manufacturer)

- The cost of acquiring the desktop analyser

- Running costs, including calibration, internal and external quality control, and maintenance

- Training (initially and continuously) on daily operation

- Instrument storage specifications, including temperature and humidity control, etc.

Detailed discussion of these aspects falls outside the scope of this article. It cannot be overemphasised that the results produced by a desktop analyser need to adhere to quality standards.

\section{Conclusion}

The consequences of ABR in terms of patient outcomes and economic impact are not a distant threat, but are being played out 'here and now'. In SA, increasing levels of MDR, XDR and PDR organisms have been spawned by rampant over-use and incorrect use of antibiotics. ${ }^{[1,58]}$ As such, antibiotics should be seen as a precious resource and the prescribing physician, particularly the GP, the guardian of this resource.

AS requires a collaborative effort on the part of policymakers, healthcare providers, healthcare insurance companies and patients. Besides the urgent need for AS governance in primary care, including optimal process and outcome measures, a drastic behavioural change is required by both doctors and patients, with more emphasis on non-antibiotic treatment options, particularly in the outpatient setting. To achieve this, primary care physicians need to assess their patients' clinical presentation carefully, attempt to follow simple frameworks for clinical decision-making regarding antibiotic use and, where applicable, make appropriate use of POCT testing of biomarkers and cultures in order to minimise diagnostic uncertainty. ${ }^{[59]}$ Understanding their patients' expectations, along with improved communication of ABR principles, education and empowerment, are key to reducing antibiotic use in the outpatient setting.

Without techniques to change behaviour, such as goal setting for GPs to reduce antibiotic prescriptions, provision of feedback to enable self-monitoring and action planning based on guidelines such as these to reduce diagnostic uncertainty, antibiotic prescribing rates will remain stagnant. ${ }^{[60]}$ Furthermore, according to the so-called 'Pareto Principle' or 'Law of the Vital Few' (derived from economic theory and implying that $80 \%$ of outcomes result from only $20 \%$ of potential causes), by focusing on a few vital interventions, one can have a significant impact on outcome with less effort. ${ }^{[61]}$ From a community stewardship point of view, it implies that even if the focus is placed on the appropriate diagnosis of ARTIs alone, this would represent a major target, with effect sizes of sufficient magnitude to have the potential to reduce the incidence of ABR bacteria in the community. ${ }^{[11]}$

Disclaimer. This clinical practice article is not intended as a sole source of guidance in the management of patients with the conditions described. Rather, it is intended to assist clinicians in decision-making. It is not intended to replace clinical judgement or establish a protocol for the care of all patients with the conditions described. These recommendations may not provide the only appropriate approach to the management of patients with such conditions.

1. Review on antimicrobial resistance. Tackling a global health crisis: Initial steps. February 2015. http:// amr-review.org/sites/default/files/Report-52.15.pdf (accessed 22 June 2015).

2. Brink AJ, Feldman C, Richards GA, Moolman J, Senekal, M. Emergence of extensive drug resistance (XDR) among Gram-negative bacilli in South Africa looms nearer. S Afr Med J 2008;98(8):586-592.

3. Dellit TH, Owens RC, McGowan JE Jr, et al. Infectious Diseases Society of America and the Society for

Healthcare Epidemiology of America guidelines for developing an institutional program to enhance Healthcare Epidemiology of America guidelines for developing an institutional prog
antimicrobial stewardship. Clin Infect Dis 2007;44(2):159-177. DOI:10.1086/510393

antimicrobial stewardship. Clin Infect Dis 2007;44(2):159-177. DOI:10.1086/510393
4. Butler CC, Dunstan F, Heginbothom M, et al. Containing antibiotic resistance: Decreased antibioticresistant coliform urinary tract infections with reduction in antibiotic prescribing by general practices. Br J Gen Pract 2007;57(543):785-792.

5. Lee GC, Reveles KR, Attridge RT, et al. Outpatient antibiotic prescribing in the United States: 2000 to 2010. BMC Med 2014;12(1):96. DOI:10.1186/1741-7015-12-96

6. Shapiro DJ, Hicks LA, Pavia AT, Hersh AL. Antibiotic prescribing for adults in ambulatory care in the USA, 2007-09. J Antimicrob Chemother 2014;69(1):234-240. DOI:10.1093/jac/dkt301

7. Gerber JS, Prasad PA, Fiks AG, et al. Effect of an outpatient antimicrobial stewardship intervention on broad-spectrum antibiotic prescribing by primary care pediatricians. A randomized trial. JAMA 2013;309(22):2345-2352. DOI:10.1001/jama.2013.6287

8. Brink AJ, Cotton M, Feldman C, et al. Updated recommendations for the management of upper respiratory tract infections in South Africa: 2015. S Afr Med J 2015;105(5):345-352. DOI:10.7196/ respiratory
samj. 8716

9. Van der Velden A, Duerden MG, Bell J, et al. Prescriber and patient responsibilities in treatment of acute respiratory tract infections - essential for conservation of antibiotics. Antibiotics 2013;2(2):316acute respiratory tract infections - esse

10. Altiner A, Knauf A, Moebes J, Sielk M, Wilm S. Acute cough: A qualitative analysis of how GPs manage the consultation when patients explicitly or implicitly expect antibiotic prescriptions. Fam Pract 2004;21(5):500-506. DOI:10.1093/fampra/cmh505

11. Brink AJ. Antimicrobial stewardship (AMS) in the community. Clin Pulm Med 2016;23(1):1-10. DOI:10.1097/CPM.0000000000000107

12. Boyles T, Wasserman, S. Diagnosis of bacterial infection. S Afr Med J 2015;105(5):419. DOI:10.7196/ SAMJ.9647

13. Wasserman S, Boyles T, Mendelson M, on behalf of the South African Antibiotic Stewardship Programme (SAASP). A pocket guide to antibiotic prescribing for adults in South Africa, 2015. http:// www.fidssa.co.za/images/SAASP_Antibiotic_Guidelines_2015.pdf (accessed 15 July 2015).

14. Hansen MP, Hoffmann TC, McCullough AR, van Driel ML, del Mar CB. Antibiotic resistance: What are the opportunities for primary care in alleviating the crisis? Frontiers Public Health 2015;3:1-7. are the opportunities for prima

15. Butler CC, Hood K, Verheij T, et al. Variation in antibiotic prescribing and its impact on recovery in patients with acute cough in primary care: Prospective study in 13 countries. BMJ 2009;338:b2242.
pation patients with acute cough
DOI:10.1136/bmj.b2242

16. Whaley LE, Businger AC, Dempsey PP, Linder JA. Visit complexity, diagnostic uncertainty, and antibiotic prescribing for acute cough in primary care: A retrospective study. BMC Fam Prac 2013;14(1):120. DOI:10.1186/1471-2296-14-120

17. National Institute for Health and Clinical Excellence guidelines. Respiratory tract infections antibiotic prescribing. Prescribing of antibiotics for self-limiting respiratory tract infections in adults and children in primary care. NICE clinical guideline 69, 2008. www.nice.org.uk/CG069 (accessed 28 October 2015).

18. Albert RH. Diagnosis and treatment of acute bronchitis. Am Fam Physician 2010;82(11):1345-1350. 19. Irwin RS. Guidelines for treating adults with acute cough. Am Fam Physician 2007;75(4):476-482.

20. Barnett ML, Linder JA. Antibiotic prescribing for adults with acute bronchitis in the United States, 1996-2010. JAMA 2014;311(19):2020-2022. DOI:10.1001/jama.2013.286141 
21. Claassen J. The sore throat. Antibiotics are overprescribed for sore throats in general practice. CME 2012;30(9):306-313

22. Sanchez GV, Hicks LA. Acute sinusitis and pharyngitis as inappropriate indications for antibiotic use Antimicrob Agents Chemother 2014;58(6):3572. DOI:10.1128/AAC.02696-14

23. Linder JE. Sore throat: Avoid overcomplicating the uncomplicated (Editorial). Ann Intern Med 2015;162(4):311-312. DOI:10.7326/M14-2899

24. Ebell MH. Point-of-care Guides. Diagnosis of streptococcal pharyngitis. Am Fam Physician 2014;89(12):976-977

25. Hernandez DR, Wolk DM. Does your 'backup' method have your back? Controversies surrounding backup of rapid antigen detection methods for group A streptococcus. Clin Micro News 2015;37(14):111-118 DOI:10.1016/j.clinmicnews.2015.07.001

26. Science $M$, Bitnun $A, M c I s a a c ~ W$. Identifying and treating group A streptococcal pharyngitis in children (Commentary). CMAJ 2015;187(1):13-14. DOI:10.1503/cmaj.141532

27. Calviño O, Llor C, Gómez F, Sarvisé C, Hernández S. Association between C-reactive protein rapid test and group A streptococcus infection in acute pharyngitis. J Am Board Fam Med 2014:27(3):424-426. DOI:10.3122/jabfm.2014.03.130315

28. Melbye H, Hvidsten D, Holm A, Nordbø SA, Brox J. The course of C-reactive protein response in untreated upper respiratory tract infection. Br J Gen Pract 2004;54(506):653-658.

29. Christensen AM, Thomsen MK, Oversen T et al. Are procalcitonin or other infection markers useful in the detection of group A streptococcal acute tonsillitis? Scand J Infect Dis 2014;46(5):376-383. in the detection of group A streptococa

30. Shulman ST, Bisno AL, Clegg HW, et al. Clinical practice guideline for the diagnosis and management of group A streptococcal pharyngitis: 2012 update by the Infectious Diseases Society of America. Clin Infect Dis 2012;55(10):e86-e102. DOI:10.1093/cid/cis62

1. Lieberthal AS, Carroll AE, Chonmaitree T, et al. The diagnosis and management of acute otitis media. Paediatrics 2013;131(3):e964-e999. DOI:10.1542/peds.2012-3488

32. Hersh AL, Jackson MA, Hicks LA, et al. Principles of judicious antibiotic prescribing for upper respiratory tract infections in pediatrics. Pediatrics 2013;132(2):1146-1154. DOI:10.1542/peds.2013-3260

33. Chow AW, Benninger MS, Brook I, et al. IDSA clinical practice guideline for acute bacterial rhinosinusitis in children and adults. Clin Infect Dis 2012:54(8):1041-1045. DOI:10.1093/cid/cir1043

34. Call SA, Vollenweider MA, Hornung CA, Simel DL, McKinney WP. Does this patient have influenza? JAMA 2005;293(8):987-997. DOI:10.1001/jama.293.8.987

35. Van Vugt SF, Broekhuizen BDL, Zuithoff NPA, Validity of a clinical model to predict influenza in patients presenting with symptoms of lower respiratory tract infection in primary care. Fam Pract 2015:32(4):408-414. DOI:10.1093/fampra/cmv039

36. Jefferson T, Jones M, Doshi P, Spencer EA, Onakpoya I, Heneghan CJ. Oseltamivir for influenza in adults and children: Systematic review of clinical study reports and summary of regulatory comments. BMJ 2014;348:g2545. DOI:10.1136/bmj.g2545

37. Healthcare Workers Handbook on Influenza - 2015. May 2015. http://nicd.ac.za (accessed 24 February 2016).

38. Wedzicha JA, Donaldson GC. Exacerbations of chronic obstructive pulmonary disease. Respir Care 2003;48(12):1204-1215

39. Anthonisen NR, Manfreda J, Warren CPW, Hershfield ES, Harding GK, Nelson NA. Antibiotic therapy in exacerbations of chronic obstructive pulmonary disease. Ann Intern Med 1987;106(2):196-204 DOI: $10.7326 / 0003-4819-106-2-196$

40. Woodhead M, Blasi F, Ewig S, et al. Guidelines for the management of adult lower respiratory tract infections. Clin Microbiol Infect 2011;17(Suppl 6):1-24. DOI:10.1111/j.1469-0691.2011.03602.x

41. Vollenwieder DJ, Jarrett H, Steurer-Stey CA, Garcia-Aymerich J, Puhan MA. Antibiotics for exacerbations of chronic obstructive pulmonary disease (Review). Cochrane Database Syst Rev 2012:12:CD010257. DOI:10.1002/14651858.CD010257

42. Llor C, Moragas A, Hernández S, Bayona C, Miravitlles M. Efficacy of antibiotic therapy for acute exacerbations of mild to moderate chronic obstructive pulmonary disease. Am J Respir Crit Care Med 2012;186(8):716-723. DOI:10.1164/rccm.201206-0996OC
43. Lim WS, Baudouin SV, George RC, et al. Pneumonia Guidelines Committee of the BTS Standards of Care Committee, The British Thoracic Society: Guidelines for the management of community-acquired pneumonia in adults: Update 2009. Thorax 2009;64(Suppl 3):iiil-iii55. DOI:10.1136/thx.2009.121434 pneumonia in adults: Update 2009. Thorax 2009;64(Suppl 3):iiil-iii55. DOI:10.1136/thx.2009.121434
44. Bartlett JG, Mundy LM. Community-acquired pneumonia. N Engl J Med 1995;333(24):1618-1624. DOI:10.1056/NEJM199512143332408

45. Cooke J, Butler C, Hopstaken R, et al. Narrative review of primary care point-of-care testing (POCT) and antibacterial use in respiratory tract infection (RTI). BMJ Open Respir Res 2015;2(1):e000086. DOI:10.1136/bmjresp-2015-000086

46. Bradley JS, Byington CL, Shah SS, et al. The management of community-acquired pneumonia in infants and children older than 3 months of age: Clinical Practice Guidelines by the Pediatric Infectious Diseases Society and the Infectious Diseases Society of America. Clin Infect Dis 2011;53(7):e25-e76. DOI:10.1093/cid/cir531

47. Plouffe JF, McNally C, File TM Jr. Value of non-invasive studies in community-acquired pneumonia. Infect Dis Clin North Am 1998;12(3):689-699. DOI:10.1016/S0891-5520(05)70205-1

48. Feldman C, Brink AJ, Richards GA, et al. Guideline: Management of community-acquired pneumonia in adults. S Afr Med J 2007;97(12):1295-1306

49. Zar HJ, Jeena J, Argent A, et al. Diagnosis and management of community-acquired pneumonia in childhood - South African Thoracic Society guidelines. S Afr Med J 2005;95(12):977-990.

50. Aabenhus R, Jensen JU, Jørgensen KI, Hróbjartsson A, Bjerrum L. Biomarkers as point-of-care tests to guide prescription of antibiotics in patients with acute respiratory infections in primary care (Review). guide prescription of antibiotics in patients with acute respiratory infections in primary care
Cochrane Database Syst Rev 2014:11:CD010130. DOI:10.1002/14651858.CD010130 pub2

51. Holm A, Pedersen SS, Nexoe J, Obel N, Nielsen LP, Koldkjaer O, Pedersen C. Procalcitonin versus $\mathrm{C}$-reactive protein for predicting pneumonia in adults with lower respiratory tract infection in primary care. Br J Gen Pract 2007;57(540):555-560

52. Dunne WM Jr. Laboratory diagnosis of sepsis? No SIRS, not just yet. J Clin Microbiol 2015;53(8):24042409. DOI:10.1128/JCM.03681-14

53. National Institute for Health and Clinical Excellence. Pneumonia: Diagnosis and management of communityand hospital-acquired pneumonia in adults. Guideline Development Group, NICE, 2014. https://www.nice. org.uk/guidance/cg191/resources/pneumonia-in-adults-diagnosis-and-management-35109868127173 (accessed 15 November 2015)

54. Van der Meer MV, Neven AK, van den Broek PJ, Assendelft WJ. Diagnostic value of $C$ reactive protein in infections of the lower respiratory tract: Systematic review. BMJ 2005;331(7507):26. DOI:10.1136/ bmj.38483.478183. EB

55. Falk G, Fahey T. C-reactive protein and community-acquired pneumonia in ambulatory care: Systematic

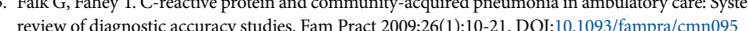

56. Sadovsky R. Value of C-reactive protein measurements in children. Am Fam Physician 1998;57:1384-1386,

57. Chew KS. What's new in emergencies trauma and shock? C-reactive protein as a potential clinical biomarker for influenza infection: More questions than answers. J Emerg Trauma Shock 2012;5(2):115117. DOI:10.4103/0974-2700.9647758.

58. Mendelson M, Matsoso MB. A global call for action to combat antimicrobial resistance: Can we get it right this time? S Afr Med J 2014;104(7):478479. DOI:10.7196/SAMJ.8534

59. Meili M, Muller B, Kulkarni P, Schutz P. Management of patients with respiratory infections in primary care: Procalcitonin, C-reactive protein or both? Expert Rev Respir Med 2015;9(5):587-601. DOI:10.1 586/17476348.2015.1081063

60. Davey P, Peden C, Charani E, Marwick C, Michie S. Time for action - improving the design and reporting of behaviour change interventions for antimicrobial stewardship in hospitals: Early findings from a systematic review. Int J Antimicrob Agents 2015;45(3):203-212. DOI:10.1016/j. ijantimicag.2014.11.014

61. Hamilton KW, Fishman NO. Antimicrobial stewardship interventions: Thinking inside and outside the box. Infect Dis Clin North Am 2014;28(2):301-313. DOI:10.1016/j.idc.2014.01.003

Accepted 11 April 2016 